\title{
Switch-Beam Vivaldi Array Antenna Based On 4x4 Butler Matrix for mmWave
}

\author{
Nurlaila Safitri ${ }^{1}$, Rina Pudji Astuti, ${ }^{1,1}$, and Bambang Setia Nugroho ${ }^{1}$ \\ ${ }^{1}$ Electrical Engineering, the School of Engineering, Telkom University. Bandung, Jawa Barat 40257, \\ Indonesia.
}

\begin{abstract}
It will be diffcult to use either omnidirectional or fixed beam antenna due to the high propagation losses caused by atmospheric absorption at mmWave for $5 \mathrm{G}$ mobile communication. Several studies have been conducted recently using butler matrix which is part of switchable antenna with some advantages such as simple, minimal cost, low loss, etc. Previous studies also have designed vivaldi array antenna at $28 \mathrm{GHz}$ which provides a fix beam directional radiation pattern with narrow beam that requires real phase setting. However, there has been no research using vivaldi antenna with butler matrix, whereas it has some advantages such as wide bandwidth, high gain, high directivity, etc. This paper proposed $4 \times 4$ butler matrix integrated with vivaldi antenna by using phase shift of 45 . The design is developed on a single layer of Rogers RT5880 with dielectric constant 2.2 and thickness $0.254 \mathrm{~mm}$. Best results of simulation were picked for overall system at $28 \mathrm{GHz}$, and the results of antenna as follows: the return loss was below $-10 \mathrm{~dB}$, the realized antennas gain was $10.2 \mathrm{~dB}$ with unidirectional radiation pattern and bandwidth antenna of $6 \mathrm{GHz}$ that covers from $25 \mathrm{GHz}$ to $31 \mathrm{GHz}$. The butler matrix average phase di erent between output port are $-44.106^{\circ}$, $137.38^{\circ},-137.66^{\circ}, 43.95^{\circ}$ with phase error of $0.894^{\circ}, 2.38^{\circ}, 2.66^{\circ}, 1.06^{\circ}$. Antenna array that has been given di erent phase by butler matrix is able to shift radiation pattern on the input port successively with range of beam that can be achieved equal to $185^{\circ}$.
\end{abstract}

\section{Introduction}

One of the challenges in making a $5 \mathrm{G}$ antenna is to design a high gain antenna to avoid high pathloss due to the atmospheric absorption of electromagnet waves at higher frequencies[1][2]. The much higher gain that is needed to compensate the higher signal attenuation at mmWave introduces the concept of antenna arrays for cellular phones[3]. But the use of antenna arrays to increase the antenna gain causes the antenna radiation pattern to be directional thus requiring the use of beam steering on the antenna [4][5].

There are two ways to steering beam using smart antenna system such adaptive array system and switched-beam [6][7][8]. Switched beam antenna is choosen because it is less cost and simple to be implement and achieve most of the features of adaptive array including capability to steer the antenna beam [6]. Butler matrix is one of the well-known

\footnotetext{
${ }^{1}$ Corresponding author: rinapudjiastuti@telkomuniversity.ac.id
} 
beam forming which can be used in switched-beam smart antenna system [9]. It is plays an important role in the transmitter and receiver for $5 \mathrm{G}$ communication with some advantages such as easy implementation [12], simple, minimal cost[10], the loss involved is very small[8][13]. This study was conducted on the basis of research [5][2] on the design of vivaldi antennas for $5 \mathrm{G}$, which integrated with 44 butler matrix [6][11] at mmWave. The working frequency of this $5 \mathrm{G}$ antenna is $28 \mathrm{GHz}$ [13][5][2].

The proposed design of butler matrix and antenna is applied for $5 \mathrm{G} \mathrm{mmWave} \mathrm{mobile}$ communication at $28 \mathrm{GHz}$. It must be capable of generating phase di erence between the output ports to provide phase di erence to the input port of antenna array. Thus, the antenna array radiation pattern is capable of shifting in certain directions according to the phase difference assigned to each input. Apart from this introductory remark, this paper has additional three sections. Section II describes the design configuration. Section III discusses the results and analysis, the performance in terms of phase di erent in output port and radiation pattern in every input will be discussed. Finally, a conclusion will be drawn in Section IV.

\section{Design Configuration}

The proposed butler matrix utilized some elements such as 90 hybrid, phased shifter of 45 and crossover. These element consists of transmission lines and calculated using microstrip feedline. It is created by copper strips separated from the ground plane by a Rogers RT5880 substrate layer with dielectric constant 2.2 and thickness $0.254 \mathrm{~mm}$ in $28 \mathrm{GHz}$.

As indicate in figure 1, the proposed design consists of a butler matrix with four inputs and four outputs, each output of the butler matrix serves as a feeding line for the vivaldi antennas and direct the beam to the desired direction according to the selected input port. The phase di erence which will be generated on each output port with the selection of input ports respectively i.e are $45^{\circ},-135^{\circ}, 135^{\circ},-45^{\circ}$.

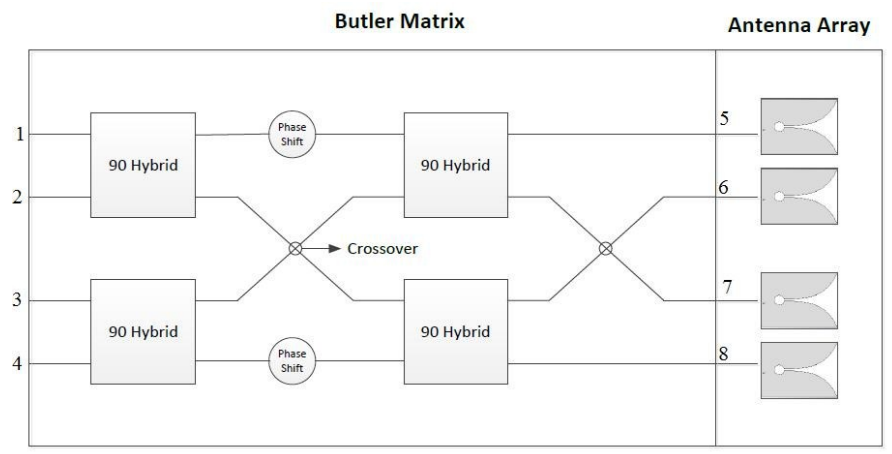

Fig 1. Design of proposed butler matrix and vivaldi array antenna

The first step to design butler matrix is design 90o hybrid which have functions as a power divider with phase margin difference at port 3 and port 4 is 90 o caused by the length of each quarter-wavelength transmission line ( $\square / 4)$. The hybrid design consists of two impedance 
namely $Z_{\mathrm{o}}$ and $\mathrm{Zo} / \square \sqrt{2} \quad$ withline length for each impedance of $\lambda / 4$.



(a)

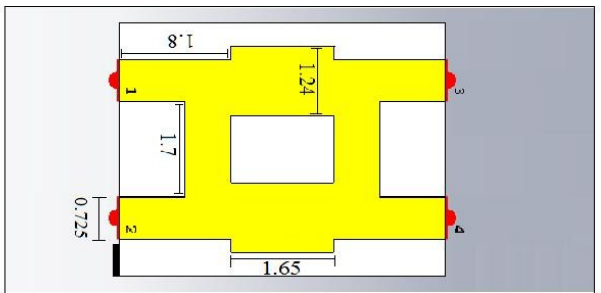

(b)

Fig 2. Configuration of 90 hybrid in (a)geometry (b)simulation

Figure 3 shows that insertion loss $S(1,3)$ and $S(1,4)$ of 90 hybrid not exactly $-3 \mathrm{~dB}$ because loss of feedline. While the isolation of $S(1.2)$ and return loss $S(1,1)$ magnitude -10 $\mathrm{dB}$ at $28 \mathrm{GHz}$ frequency. The phase di erence between the output ports $\mathrm{S}(1.3)$ and $\mathrm{S}(1.4)$ is approaching 90 which has been in accordance with the desired hybrid specification.

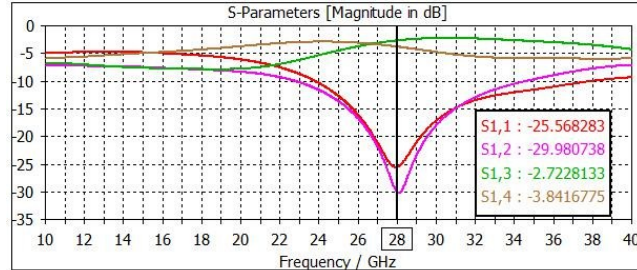

(a)

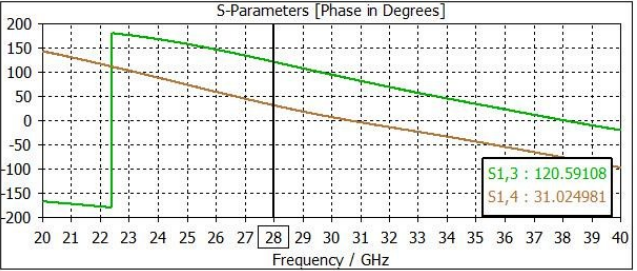

(b)

Fig 3. Simulation result (a)insertion loss, return loss and isolation (b)phase di erent

The second step is design and simulate the crossover which used for obtain high isolation between two intersecting lines in order not to connect electrically by combining the 90 hy-brid in series, but it does not give satisfactory performance[11]. Therefore, the geometry used is shown in Figure 4 where mitred bend is used to prevent discontinuity on the crossover.

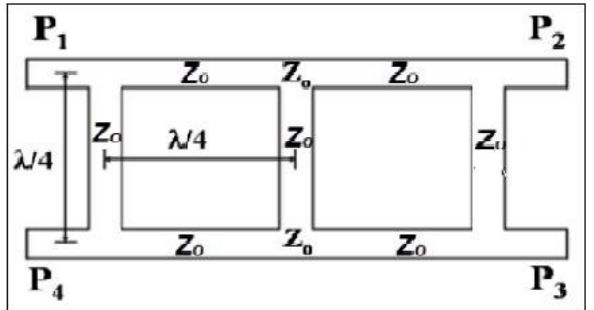

(a)



(b)

Fig 4. Configuration of crossover in (a)geometry (b)simulation

The result of crossover simulation after optimized is showed in Figure 5, the insertion loss $\mathrm{S}(1,4)$ value is about to $0 \mathrm{~dB}$ due to channel loss. While the return loss $\mathrm{S}(1,1)$ and isolation 
$\mathrm{S}(2,1)$ and $\mathrm{S}(3,1)$ values are less than $-10 \mathrm{~dB}$, which means that almost nothing is missed on those ports.

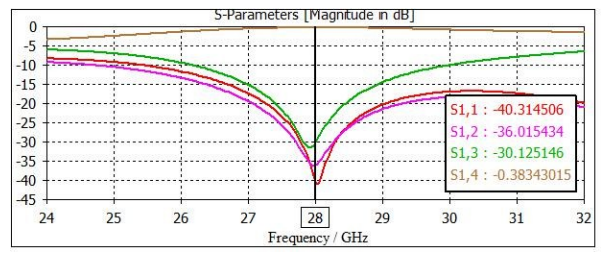

Fig 5. S-Parameter at $28 \mathrm{GHz}$ for crossover

The third step is design and simulate the phase shift which used for steered beam antenna in the desired direction without repositioning the antenna physically [9][10]. The phase out-put at the phase shifter can be seen in figure 6 where at $28 \mathrm{GHz}$ frequency, the phase output is approaching $-45^{\circ}$

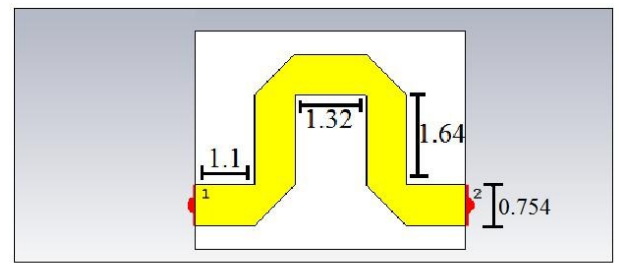

Fig 6. Geometry of phase shifter after optimization

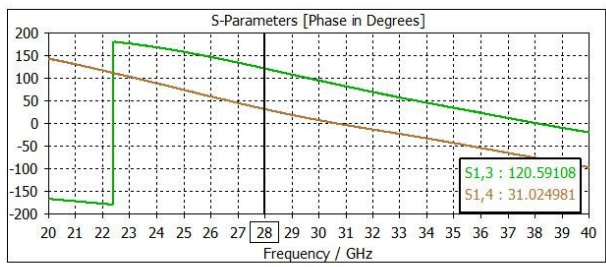

(b)

The final step is design and simulate a vivaldi antenna to an array. Vivaldi antenna config-uration is obtained based on [13] and modified the vivaldi input to make distance of vivaldi input as sama as butler matrix. The optimized vivaldi can be seen in Figure 7 where the vivaldi dimension is $6.6 \mathrm{~mm} 9 \mathrm{~mm}$.



Fig 7. Optimum design of vivaldi antenna at $28 \mathrm{GHz}$.

The return loss value $S(1,1)$ and radiation pattern of vivaldi antenna is shown in Figure 8. The return loss value at $28 \mathrm{GHz}$ is $-24.09165 \mathrm{~dB}$ which is less than $-10 \mathrm{~dB}$ while bandwidth antenna is $6 \mathrm{GHz}$. It is also has unidirectional radiation pattern with realized gain about $4.13 \mathrm{~dB}$. 




(a)



(b)

Fig 8. Result of vivaldi simulation (a)returnloss (b)radiation pattern

\section{Result and Analysis}

Hereafter, all the individual components of butler matrix are combined on a single substrate together without antenna, it has dimension of $20.52 \mathrm{~mm} 26.4 \mathrm{~mm}$. After the butler matrix has been designed to provide the output of phase di erence of $45^{\circ},-135^{\circ}, 135^{\circ},-45^{\circ}$ on the output port, then it was integrated with four vivaldi antennas which has been designed, the final design of butler matrix-antenna array is shown in Figure 9 with dimension of $20.52 \mathrm{~mm} 29.52 \mathrm{~mm}$.

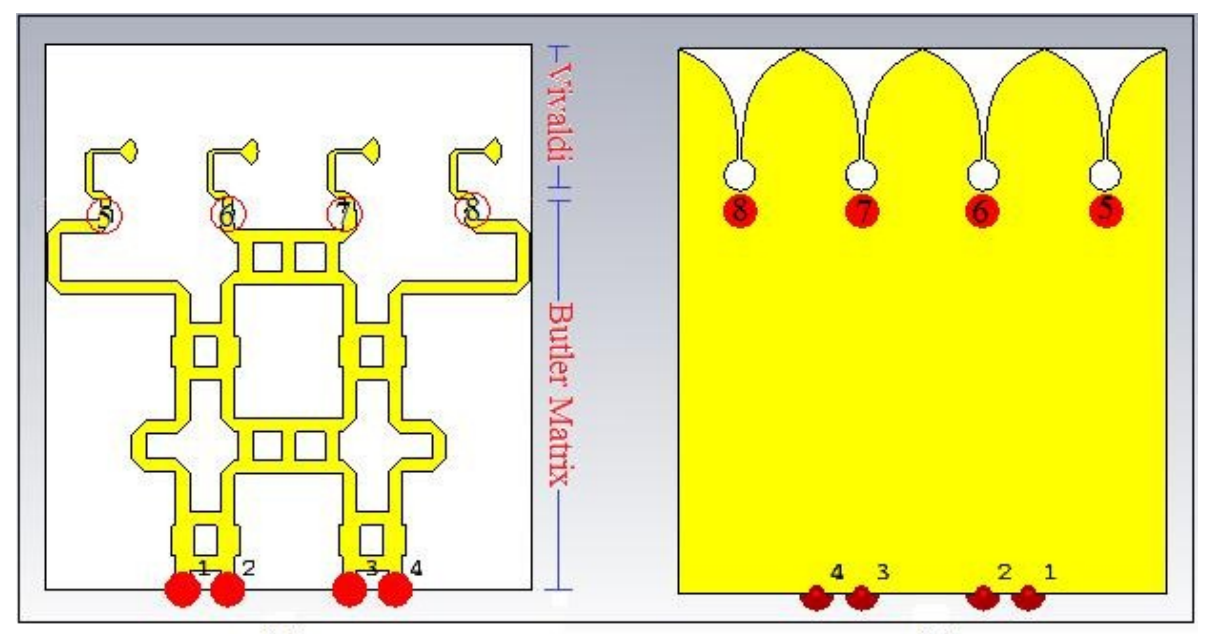

(a)

(b)

Fig 9. Simulation of butler matrix array (a)top side (b)bottom side

Table 1. The phase di erence between butler matrix output ports

\begin{tabular}{|c|c|c|c|c|c|c|}
\hline \multirow{2}{*}{$\begin{array}{l}\text { Input } \\
\text { Port }\end{array}$} & \multicolumn{3}{|c|}{$\operatorname{Port}\left({ }^{\circ}\right)$} & \multirow{2}{*}{ Average $\left({ }^{\circ}\right)$} & \multirow{2}{*}{$\begin{array}{l}\text { Theoritical } \\
\text { Target }\left({ }^{\circ}\right)\end{array}$} & \multirow[b]{2}{*}{ Error $\left({ }^{\circ}\right)$} \\
\hline & $5-6$ & $6-7$ & $7-8$ & & & \\
\hline 1 & -43.49 & -47.02 & -41.81 & -44.106 & -45 & 0.894 \\
\hline 2 & 150.85 & 114.63 & 146.66 & +137.38 & +135 & 2.38 \\
\hline 3 & -146.46 & -115.7 & -150.83 & -137.66 & -135 & 2.66 \\
\hline 4 & 41.82 & 46.67 & 43.38 & 43.95 & +45 & 1.06 \\
\hline
\end{tabular}


It can be seen from Table 1 which obtained through simulation with phase error on the output port of butler matrix respectively are $0.894,2.38,2.66,1.06$. While radiation pattern of butler matrix-vivaldi array antenna in every port are shown in Figure 10.



(a)

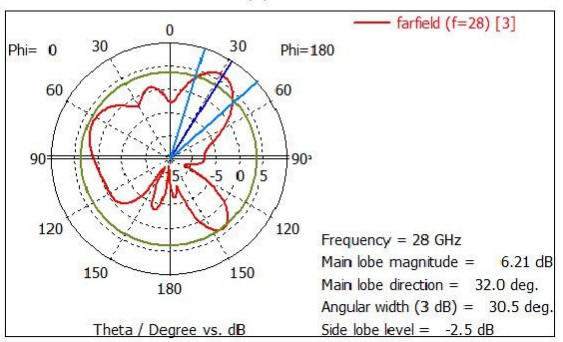

(c)



(b)

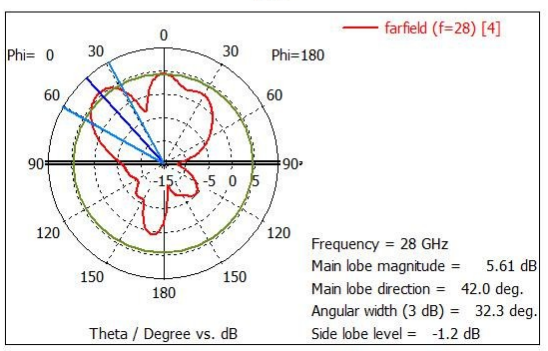

(d)

Fig 10. Radiation pattern in every input (a)Port 1 (b)Port 2 (c)Port 3 (d)Port 4

The antenna radiation pattern on each input port when all input ports are combined can be seen in Figure 11. It shows that antenna radiation pattern changes depends on the phase di erence given in each di erent input. The main lobe direction obtained successively on port $1,2,3,4$ successively $-141.1^{\circ},-29^{\circ}, 32^{\circ}, 42^{\circ}$. The main lobe direction which is not symmetrical due to the phase di erence in the output port varies in value. To obtain the sequential beam shift from the data, the sequence of input ports selected are 1, 4, 2, 3 with maximum beam range is 185 in azimuth plane.

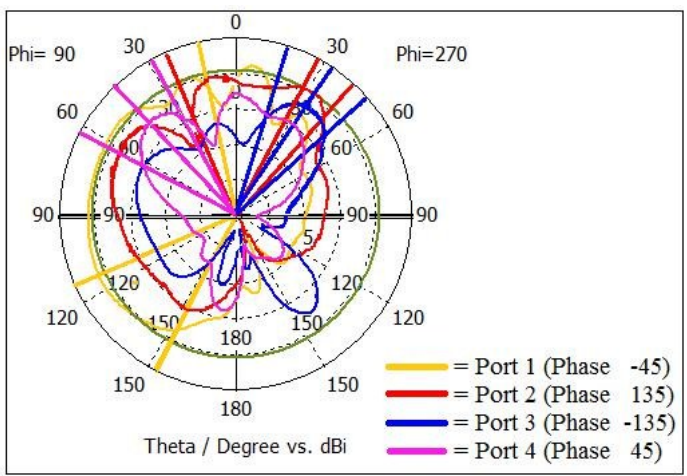

Fig 11. Radiation pattern in every input 


\section{Conclusion}

This paper presents a $4 \times 4$ butler matrix using vivaldi array antenna at mmWave for $5 \mathrm{G}$ mobile communication. All component of butler matrix such as $90^{\circ}$ hybrid, crossover and phase shifter are designed individually. Vivaldi antenna simulation result showed that the antenna can cover from $25 \mathrm{GHz}$ to $31 \mathrm{GHz}$ with the highest array gain performance of 10.2 $\mathrm{dBi}$ at $28 \mathrm{GHz}$. The simulation results of the butler matrix demonstrated a good performance at operating frequency in terms of S-parameters and phase differences in output port. The beam can be switched toward in different directions by switching any of the input ports which will be suitable for $5 \mathrm{G}$ mobile communication which would support the future $5 \mathrm{G}$ and operate at $28 \mathrm{GHz}$ of frequency. Thus, it has intended to get the butler matrix-vivaldi antennas fabricated and tested to validate the design method. The fabrication will be done in a place where fabrication and measurement equipment are available.

\section{References}

1. A. Kumar and P. Kapoor, "Design and Performance Evaluation of a Dual- Band Antenna for the 5G Mobile Communication," pp. 2034-2036, 2016.

2. A. Rahman, A. El, and B. Ahmed, "Design of Vivaldi Antenna Array with Enhancement of Radiation Characteristics for 5G Mobile Applications Design of Vivaldi Antenna Array with Enhancement of Radiation Characteristics for 5G Mobile Applications," no. March, 2017.

3. W. Hong, K. H. Baek, Y. Lee, Y. Kim, and S. T. Ko, "Study and prototyping of practically large-scale mmWave antenna systems for 5G cellular devices," IEEE Commun. Mag., vol. 52, no. 9, pp. 63-69, 2014.

4. N. Ojaroudiparchin, M. Shen, and G. F. Pedersen, "Design of Vivaldi antenna array with end-fire beam steering function for 5G mobile terminals," 2015 23rd Telecommun. Forum, TELFOR 2015, pp. 587-590, 2016.

5. W. Hong, "Solving the Antenna Puzzle," no. October 2017.

6. S. Ifeoma, "A 4x4 Butler Matrix for $28 \mathrm{GHz}$ Switched Multi-Beam Antenna A 4x But-ler Matrix for $28 \mathrm{GHz}$ Switched Multi-Beam Antenna," vol. 7, no. February 2016, pp. 436-442, 2015.

7. H. Nachouane, A. Najid, A. Tribak, and F. Riouch, "Broadband 4X4 Butler matrix using wideband 90; hybrid couplers and crossovers for beamforming networks," 2014 Int. Conf. Multimed. Comput. Syst., no. APRIL, pp. 1444-1448, 2014.

8. W. Bhowmik and S. Srivastava, "Optimum Design of a $4 \times 4$ Planar Butler Matrix Array for WLAN Application,” vol. 2, no. 1, pp. 68-74, 2010.

9. P. F. I. Shaikh and S. B. Akhade, "Smart Antenna System using 4x4 Butler Matrix switched beam network for 2 . 4 GHz ISM band," vol. 4, no. 3, pp. 278-282, 2015.

10. S. V. Kalam and A. B. Rathi, "Optimum Design of 4X4 Symmetrically Structured Butler Matrix," vol. 5, no. 1, pp. 31-34, 2016.

11. H. Abdul and R. Al, "Design of a 4x4 Butler Matrix for Vehicle Radar Beamforming Antenna systems at $24 \mathrm{GHz}$ By Hani Abdul Rahman Al Habibi."

12. Firmansyah, T. Praptodinoyo, S. et al. "Dual-wideband band pass filter using folded cross-stub stepped impedance resonator". Microwave and Optical Technology Letters.Vol.59(11). pp. 2929-2934. November 2017.

13. Firmansyah,T. et al. "Hepta-band bandpass filter based on folded cross-loaded stepped impedance resonator". Electronics Letters(2017), vol. 53 (16):1119.

14. M. Bouezzeddine, W. L. Schroeder, and T. Kaiser, "On the Design of MIMO Antennas for Cognitive Radio Systems," vol. 2, no. 2, pp. 2-6.

15. G. K. Pandey, H. S. Singh, P. K. Bharti, a. Pandey, and M. K. Meshram, "High Gain Vivaldi Antenna for Radar and Microwave Imaging Applications," Int. J. Signal Process. Syst., vol. 3, no. 1, pp. 35-39, 2014. 